\title{
COVID -19 Infection and the Steps to be Taken in a Medical Laboratory
}

\section{Sultana T*}

Laboratory Medicine, Bangabandhu Sheikh Mujib Medical University, Bangladesh

*Corresponding author: Dr. Tuhin Sultana, Professor and Chairman, Laboratory medicine, Bangabandhu Sheikh Mujib Medical University (BSMMU), Bangladesh, Tel: +8801711300400; Email: drtsultana@gmail.com
Editorial

Volume 4 Issue 1

Received Date: May 19, 2020

Published Date: May 28, 2020

DOI: $10.23880 /$ cprj-16000123

\section{Editorial}

COVID-19 is a contagious disease. This virus mainly infects throat and lungs. This disease spreads through the infected person's cough, sneeze, respiratory droplets or contact of the person. If infected by this virus the symptoms which will be seen in the infected person are given below:
a. Fever, Sneezing, Cough
b. Running nose and nasal obstruction
c. Sore Throat, Stomachache, Loose motion
d. Bodyache, Dyspnoea, Tightness in the chest and Chest Pain

e. Reduction in taste sensation

The patients who have these given symptoms should go to Medical Universities, Government and Private Hospitals, Consultation \& Diagnostic centres. Then the doctors or specialists will give instructions for conducting some investigations for determining the disease.Most of these tests are done in the clinical laboratories of different hospitals. As the sample of the tests the blood, serum, cough, urine, stool, body fluid, nasal swab, tracheal swab, throat swab etc. comes. While working with these samples the doctors, biochemists, medical technologists, technician, lab attendant and the other staffs of the lab have many possibilities to be infected by this virus.

The possibilities are:

a. From the sample of the infected persons routine Haematology tests.

b. From the serum or plasma of routine biochemistry samples.

c. From the sneeze or cough of the symptomless infected person while giving samples. d. From the relatives of the symptomless infected person who have come in contact with the infected person.

e. From the sample of the symptomless infected person who has come to give samples for other diseases.

In the meantime community transmission has occurred in small scale or in clusters. So it is required to be conscious because if someone in the laboratory is infected there is possibility for others to be infected such as:
a. Staff himself
b. Colleagues
c. Other patients or their relatives.
d. His or her family
e. He himself

Ultimately he or she can cause community transmission. So it is very important for the laboratory staffs to be safe.

The factors which are responsible for the infection in the labs are:

a. The needle pricks injury during blood collection from the veins of the infected person.

b. If the tube breaks while getting out the tube topper from the sample tube. There can also be spilling of the infected persons blood.

c. While conducting pipetting through mouth.

d. If the sample spills to the skin and mucus membrane.

e. While testing the body fluids.

f. While making cough smear.

g. While making blood smear.

h. If the gloves are infected. 
i. If aerosol comes out of centrifuge machines.

j. During stool preparation.

There is no way other than awareness \& protection to prevent accidents in the medical laboratory. Awareness \& protection can only give rescue from COVID-19. The staffs of the laboratory can keep themselves safe in the given ways:

Maintenance of the General Rules of the Laboratory

a. Will have to obey all the general rules of the laboratory strictly.

b. Will have to abide by the SOP (Standard Operating Procedure).

c. Sufficient PPE (Personal Protection Equipment) should present

d. To give training of using PPE.

e. All protection items should be kept in a separate room.

f. To identify the sick staffs and setting a work plan for them because they are in high risk.

g. It is required to review the rules of cleanliness and hygiene with the staffs and give them instructions.

$\mathrm{h}$. While working it is required to maintain social distance as per WHO.

i. Reduction of stress regarding work.

j. It is required to ensure the security of the family.

$\mathrm{k}$. It is required to take enough rest.

l. It is required to conduct meetings, briefing maintaining social distance.

m. It is required to fix overtime for the staffs.

n. It is required to fix the roaster of duties of the staffs in such a way that all the staffs do not work together because there is risk in transmission among staffs if there are more people.

o. Food and liquids shouldn't be allowed in the laboratory.

\section{Personal Security in the Laboratory}

a. It is required to wear long sleeve clothes.

b. It is required to tie the hair.

c. To use cream or makeup is prohibited.

d. Before going out from it is require cleaning the hands using soap or sanitizer. e. To clean the personal items using anti-bacterial substance and putting them into a separate bag.

f. It is required to avoid public transport as much as possible.

g. It is required to wash the hands while entering the lab.

h. It is required to wear the laboratory uniform or PPE.

i. Wearing mask is compulsory (N-95 or surgical mask). It is also required to wear gloves, goggles and apron.

j. It is required to wear shoe cover.

k. After seeing a sample it is required to change the gloves and throw them into a covered bin or into a disposal bag.

1. It is required to use one tissue only one time and throw the tissue into a disposal bag.

$\mathrm{m}$. If one touches the phone, remote, filter and other things of the lab in duty he or she should clean his or her hands using Hexisol or sanitizer.

n. After finishing the work the PPE should be thrown into the disposal bag.

o. It is required to keep the apron and other things in the lab.

p. One shouldn't touch his or her face with unclean hands.

q. It is required to wash hands and then get out of the lab.

r. After reaching home,one should keep his or her personal belongings into a separate bag after cleaning it with antibacterial substances.

s. One should bathe as soon as reaching home and should wash the clothes with soap in a separate.

t. One shouldn't touch taka or currencies if one touches he/she should wash his /her hands with soap.

In most of the laboratories the work of Hematology, Clinical Pathology, Microbiology and Biochemistry department's work are done together, so infected sample can come easily. So if carefulness isn't present then the virus can spread easily. If someone of the staff is infected then all the staff of the lab might have to go to isolation. Then determination of the diseases of the normal patients will come into risk. The treatment of the other patients will have hampered. The lives of the patients will come into risk. So in these circumstances to avoid transmission of COVID-19 personal safety is the best and only way to protect the laboratory staffs. 